\begin{tabular}{|l|l|l||}
\hline \multicolumn{2}{|c|}{ PublisherInfo } \\
\hline \hline PublisherName & $:$ & BioMed Central \\
\hline \hline PublisherLocation & $:$ & London \\
\hline \hline PublisherImprintName & $:$ & BioMed Central \\
\hline \hline
\end{tabular}

\title{
Dopamine raises ICP
}

\begin{tabular}{|l|l|l||}
\hline \multicolumn{2}{|c||}{ ArticleInfo } \\
\hline \hline ArticleID & $:$ & 4304 \\
\hline \hline ArticleDOI & $:$ & $10.1186 /$ ccf-2001-73300 \\
\hline \hline ArticleCitationID & $:$ & 73300 \\
\hline \hline ArticleSequenceNumber & $:$ & 15 \\
\hline \hline ArticleCategory & $:$ & Paper Report \\
\hline \hline ArticleFirstPage & $:$ & 1 \\
\hline \hline ArticleLastPage & $:$ & 3 \\
\hline \hline & & RegistrationDate : 2001-12-4 \\
ArticleHistory & $:$ & Received \\
\hline ArticleCopyright & $:$ 2001-5-14 \\
\hline \hline ArticleGrants & $:$ & OnlineDate \\
\hline \hline ArticleContext & $:$ & 1305455 \\
\hline \hline
\end{tabular}


Aff1 Christiana Care Health Systems, Wilmington, Delaware, USA

\section{Keywords}

Craniocerebral trauma, dopamine, intracranial pressure, norepinephrine

\section{Context}

The simple equation of cerebral perfusion pressure $(\mathrm{CPP})=$ mean arterial pressure (MAP) intracranial pressure (ICP), has guided management and prevention of secondary brain injury for nearly as long as traumatic head injuries have occurred. Maintaining CPP greater than $60-70 \mathrm{mmHg}$ theoretically protects viable brain from ischemic injury that may result from edema and hemodynamic instability following severe head trauma. Vasopressors have been used to manipulate peripheral vascular tone and keep MAP elevated, without significantly decreasing cerebral blood flow (due to autoregulation). The authors note that no studies have effectively analyzed the effects of specific vasopressors on ICP, particularly in the setting of a possibly disrupted blood brain barrier.

\section{Significant findings}

In patients with traumatic brain injuries, with MAP constant, there was no statistically significant difference in $\mathrm{PaCO}_{2}$, blood flow velocity in the middle cerebral artery $(\mathrm{Vm})$, jugular venous oxygen saturation $\left(\mathrm{SjvO}_{2}\right)$, and aortic output $(\mathrm{AO})$. Heart rate, however, was significantly higher with dopamine than with norepinephrine. ICP was significantly higher, and CPP significantly lower, with dopamine infusions in both groups. This difference in ICP was not correlated with any variation of MAP, HR, Vm, $\mathrm{SjvO}_{2}, \mathrm{AO}, \mathrm{PaO}_{2}$ or $\mathrm{PaCO}_{2}$.

\section{Comments}

The design of the study was clever, though riddled with bias between 'groups'. Initial choice in pressor, a significant difference in $\mathrm{PaCO}_{2}$, heart rate variation and higher dose requirement of pressor all suggest an inequality between groups with the second group being 'sicker'. The study design sidesteps 
this issue with the pressor crossover. The authors postulated that elevated ICP with dopamine is due to dopamine-induced cerebral vasodilatation. The theory is that cerebral blood volume is increased without increasing cerebral blood flow (CBF) due to an induced decrease of CPP. The authors remain unconvincing of this point. The authors point to studies that show topically applied, low-dose dopamine causing arterial relaxation and, consequently, increasing CBF without affecting cerebral metabolism. That ICPs are higher in patients treated with dopamine warrants further research. The roles of autoregulation and the blood brain barrier are not clearly defined. Also unexplained is the lack of a significant decrease in $\mathrm{SjvO} 2$ and increased $\mathrm{Vm}$ (documenting increased $\mathrm{CBF}$ ) that should have occurred due to ?-agonist-mediated increase in cerebral metabolism in patients given norepinephrine. The perceived difference in magnitude of higher ICP's between the two groups (in relation to which pressor they received first) was explained in terms of autoregulatory mechanisms, where a decreased MAP induces a greater increase in ICP than an increased MAP induces a decrease in ICP (vasoconstriction less than vasodilatation). Assuming that dopamine causes a modest increase in ICP, there may be a difference in magnitude of this increased ICP, depending on which pressor is given first.

\section{Methods}

A prospective crossover clinical trial.

\section{Additional information}

\section{References}

1. Ract C, Vigue B: Comparison of the cerebral effects of dopamine and norepinephrine in severely head-injured patients. Intensive Care Med . 2001, 27: 101-106. 